\title{
Corrigendum: Design and Preliminary Feasibility Study of a Soft Robotic Glove for Hand Function Assistance in Stroke Survivors
}

\author{
Hong Kai Yap ${ }^{1,2}$, Jeong Hoon Lim ${ }^{3}$, Fatima Nasrallah ${ }^{4}$ and Chen-Hua Yeow ${ }^{1 *}$ \\ ${ }^{1}$ Department of Biomedical Engineering, National University of Singapore, Singapore, Singapore, ${ }^{2}$ NUS Graduate School for \\ Integrative Sciences and Engineering, National University of Singapore, Singapore, Singapore, ${ }^{3}$ Department of Medicine, \\ National University of Singapore, Singapore, Singapore, ${ }^{4}$ Queensland Brain Institute, University of Queensland, St. Lucia, \\ QLD, Australia
}

Keywords: soft robotic, hand exoskeleton, rehabilitation, activities of daily living, soft actuators

\section{OPEN ACCESS}

Edited and reviewed by:

Frontiers in Neuroscience Editorial

Office,

Frontiers, Switzerland

*Correspondence:

Chen-Hua Yeow

rayeow@nus.edu.sg

Specialty section:

This article was submitted to

Neural Technology,

a section of the journal

Frontiers in Neuroscience

Received: 18 April 2018

Accepted: 25 April 2018

Published: 08 May 2018

Citation:

Yap HK, Lim JH, Nasrallah F and

Yeow C-H (2018) Corrigendum: Design and Preliminary Feasibility

Study of a Soft Robotic Glove for Hand Function Assistance in Stroke Survivors. Front. Neurosci. 12:323.

doi: 10.3389/fnins.2018.00323

\section{A corrigendum on}

Design and Preliminary Feasibility Study of a Soft Robotic Glove for Hand Function Assistance in Stroke Survivors

Yap, H. K., Lim, J. H., Nasrallah, F., and Yeow, C.-H. (2017). Front. Neurosci. 11:547. doi: 10.3389/ fnins.2017.00547

In the original article, there was an error in the stated funding support. The correct Funding Statement appears below.

\section{FUNDING}

This work was funded by the A*STAR Medtech Innovation Grant (R397-000-260-305) and the National University Health System (NUHS)-Clinical Imaging Research Center (CIRC) Seed Funding Grant (R-172-000-323-511).

The authors apologize for this oversight. This error does not change the scientific conclusions of the article in any way.

The original article has been updated.

Conflict of Interest Statement: The authors declare that the research was conducted in the absence of any commercial or financial relationships that could be construed as a potential conflict of interest.

Copyright (c) 2018 Yap, Lim, Nasrallah and Yeow. This is an open-access article distributed under the terms of the Creative Commons Attribution License (CC BY). The use, distribution or reproduction in other forums is permitted, provided the original author(s) and the copyright owner are credited and that the original publication in this journal is cited, in accordance with accepted academic practice. No use, distribution or reproduction is permitted which does not comply with these terms. 